\title{
Apuntes sobre estudios tempranos de videojuegos en Iberoamérica
}

\author{
Notes on early video game studies in Iberoamerica
}

Álvaro Alfonso Acevedo Merlano ${ }^{1}$

\section{Resumen}

Este ensayo bibliográfico aborda algunas investigaciones realizadas en las dos últimas décadas sobre el consumo de videojuegos y su incidencia en las subjetividades de los jugadores Iberoamericanos y ayuda a comprender cómo las subjetividades son afectadas de diferentes formas dependiendo de las características de los videojuegos que son consumidos; mostrando de esa manera cómo el fenómeno de los videojuegos se encuentra más diseminado de lo que generalmente se piensa. En consecuencia, los resultados plantean que las subjetividades de los video-jugadores se construyen mediante las interrelaciones que se producen entre los sujetos y la dinámica en la que se desarrolla el juego, incorporando a su constructo tanto valores como sentimientos y significados.

Palabras Clave: consumo; cultura; Iberoamérica; videojuegos.

\section{Abstract:}

This bibliographic essay addresses some research carried out in the last two decades on video game consumption and its impact on the subjectivities of Iberoamerican players and helps to understand how subjectivities are affected in different ways depending on the characteristics of the video games that are consumed; showing in this way how the phenomenon of video games is more widespread than is generally thought. Consequently, the results suggest that the subjectivities of the video players are constructed through the interrelationships that occur between the subjects and the dynamics in which the game develops, incorporating values, feelings and meanings into its construct.

Keywords: Consumption; culture; Iberoamerica; videogames.

1 Máster en Educación, línea cibercultura. Maestría en comunicación y desarrollo. Antropólogo. Profesor investigador Universidad de la Costa.Colombia alvaroacevedomerlano@gmail.com : https://orcid.org/0000-0002-0131-0276 


\section{Introducción}

El fenómeno de los videojuegos ha tenido una gran propagación en las últimas décadas, a causa de la inclusión de las nuevas tecnologías de la información y la comunicación en la vida cotidiana de occidente. Su difusión y consumo ha sido tan amplia que actualmente es una de las industrias culturales más poderosas del planeta, compitiendo par a par con la industria del cine.

Pero ¿qué son los videojuegos? La Real academia de la Lengua Española (2019) los define como: "el dispositivo electrónico que permite, mediante mandos apropiados, simular juegos en las pantallas de un televisor o de un ordenador." Entonces se puede argumentar que los videojuegos son la articulación entre lo que se entiende tradicionalmente como juego y las nuevas tecnologías de la información y la comunicación (Acevedo y Chaux, 2016). Así, los videojuegos se han convertido en uno de los pasatiempos más practicado por la juventud contemporánea, sin la excepción de otros grupos etarios.

En ese sentido, los videojuegos, especialmente en los online, en donde existe una gran cantidad de personas interactuando, a veces a nivel masivo y simultáneamente, se generan un gran cúmulo de relaciones que dependiendo del título pueden entrenar al jugador en habilidades como la tolerancia a la frustración, el fomento para trabajar en equipo, el desarrollo del liderazgo y la negociación, o, por otra parte, pueden incentivar a la construcción de conocimiento de manera colectiva y conectiva (Acevedo y Chaux, 2018).

Algunos juegos también pueden enseñar a los jugadores respecto a las maneras de relacionarse con los demás, ya que se pueden generar penalizaciones desde la colectividad en rechazo a un comportamiento considerado como negativo, deshonesto o anti cooperativo. A tenor de lo expuesto, se puede observar que mediante estas coerciones sociales los jugadores moldean su comportamiento, ya que aprenden por vía propia cómo sus acciones traen consecuencias negativas o positivas, contribuyendo de esa manera a forjar algunas habilidades y destrezas sociales.

En los últimos años los videojuegos también han incursionado en el campo de lo educativo, donde han demostrado un gran potencial en el fomento del aprendizaje significativo, ya que, en el ejercicio de jugar con videojuegos, no sólo se está asimilando la información que éste proporciona al jugador, ya que el elemento de la interactividad juega un papel fundamental que diferencia a los videojuegos como dispositivos propicios para el aprendizaje de otros mecanismos de enseñanza (Acevedo-Merlano, 2019).

En ese sentido, el sujeto no sólo se acerca a la información, sino que logra una mayor sensibilidad gracias a la experiencia vivida, desarrollada por la interacción y la 
posibilidad que tiene el jugador de interferir en la secuencia que el videojuego propone, garantizando de esa manera que lo aprendido sea mucho más significativo y duradero.

Por lo tanto, resulta importante acercarse a las potencialidades que estos dispositivos de juego poseen en la construcción de las subjetividades de los jugadores, mientras que a través de la interactividad de los entornos virtuales continúan expandiéndose las relaciones, alianzas y redes creadas por los jugadores a lo largo y ancho del globo. Ahora bien, para el caso de Hispanoamérica los videojuegos se encuentran en más lugares de los que se cree; en muchas ciudades pequeñas, pueblos y hasta veredas existen salas de VJ que evocan a los primeros salones recreativos de Arcades de los años 80's descritas por Belli y López (2008), en los que por unas cuantas monedas se podía jugar en alguna de estas grandes consolas. No obstante, estas salas a las que se hace referencia están conformadas por consolas que fueron diseñadas exclusivamente para uso doméstico, consolas caseras como Xbox, Nintendo, PlayStation, Sega, etc., se encuentran presentes en estos lugares, donde se cobra lo equivalente a 1 USD por cada hora de juego, en contraste con las salas de Arcades en donde la moneda duraba lo que el jugador podía permanecer sin perder su turno hasta finalizar el juego.

Estos establecimientos conocidos simplemente como salas de videojuegos funcionan gracias a la apropiación que tuvieron los sectores populares sobre estas tecnologías, al adaptar estos aparatos que fueron diseñados desde su concepción como dispositivos para el espacio doméstico, convirtiéndolos hoy en día en los principales responsables de la difusión popular de los videojuegos en el ámbito de lo público a lo largo de las urbes y poblados hispanoamericanos.

Asimismo, dinámicas como la piratería, el contrabando y la informalidad son elementos significativos para que en estos lugares también se lleve a cabo un consumo masivo de videjuegos, pues a pesar de ser sitios con recursos económicos limitados, logran acceder en última instancia a estas tecnologías de juego (García-Carrizo, 2016; Torres-Parra, 2013; Rodríguez y Pestano, 2012).

\section{Desarrollo}

\section{Estudios tempranos sobre videojuegos en Iberoamérica}

Hace 20 años la bibliografía sobre videojuegos no era tan extensa; sin embargo, en estas dos últimas décadas este campo de estudio ha mostrado un gran aumento en el interés de diferentes disciplinas, principalmente la psicología, el interés creciente sobre el estudio de VJ puedes ser a causa del aumento acelerado que ha tenido esta industria cultural en la última década. Cada día más y más personas consumen esta forma de entretenimiento, lo que ha llamado la atención de profesionales en diversas disciplinas, inclusive existe ya todo un campo interdisciplinar conocido como "gamestudies" que se caracteriza por conformarse por una gran cantidad de profesiones de 
diferentes áreas y con diferentes enfoques, desde la medicina, hasta las humanidades y el arte (Mayra, 2008). La mayoría de la información encontrada y que sirve como sustrato para esta investigación es documentación localizada en el internet.

Desde ese contexto iniciamos con Muros, Aragón y Bustos (2013) quienes se centran en la comprensión de los comportamientos de los jóvenes de secundaria en su tiempo libre, mientras usan diversos entornos virtuales. Es el resultado de una investigación llevada a cabo en un centro de servicios comunitarios, formativos y de ocio dirigido a la población juvenil. A raíz de que dicho centro ofrece diversas posibilidades para el uso de herramientas tecnológicas y digitales en cuanto a las actividades lúdicas propuestas, el estudio se centra en el análisis sobre las motivaciones en el uso de las herramientas tecnológicas y las reflexiones de los jóvenes respecto a las interacciones que se dan en dichos entornos y los modelos de convivencia.

Se analizan las relaciones que se generan entre los espacios virtuales y físicos, centrándose en la construcción de las interacciones de una manera vivencial, con el propósito de comprender las situaciones que motivan y los comportamientos que la juventud analizada tienen sobre las nuevas maneras de socializar en red, específicamente, lo relacionado a la búsqueda del placer, el entretenimiento, el establecimiento de relaciones sociales y la estimulación continua en los usos (Muros; Aragón y Bustos, 2013).

Por su parte Aragón (2011) demuestra su intención en transformar las connotaciones negativas que aún poseen los videojuegos en la sociedad occidental contemporánea, como tecnologías que propician la adopción de comportamientos antisociales y reproductores de sexismos o agresividad. El trabajo se propone mostrar las potencialidades de los videojuegos como herramientas mediadoras en el proceso de construcción de la identidad social de los jóvenes, y también útiles para el fortalecimiento de competencias relacionadas a los procesos de alfabetización digital.

Se elabora una disertación sobre qué se entiende por videojuegos y sus características; seguidamente, la autora hace un recorrido por los diversos mitos que se han construido alrededor de estas tecnologías de juego, como el mito de la violencia y del sexismo. Asimismo, se plantea la idea de entender a los videojuegos como herramientas de construcción social y cultural. Finalmente, propone que los videojuegos deben ser entendidos como parte de la realidad de los jóvenes y por tanto deben ser tenidos en cuenta para advertir a los jugadores de sus peligros, transformando sus contenidos en temas educativos aprovechando sus potencialidades en cuanto al entrenamiento en la resolución de problemas y la creatividad.

Del Villar (2011) se centra en categorías de análisis psicológicas, haciendo referencia a la característica hipertextual de los videojuegos y ubicando su investigación en diferentes grupos etarios, principalmente en jóvenes y niños, valiéndose de 


\section{CIENCIAS SOCIALES}

herramientas estadísticas indaga en el consumo de los mismos y caracterizando los diferentes tipos: "juegos de acción, juegos de aventura, juegos de simulación y juegos de reflexión”, con el fin de evidenciar la incidencia del estrato socioeconómico respecto al consumo y cómo cada tipo de estos videojuegos posee un simplicidad y complejidad según el análisis realizado por el autor. Algunos de sus planteamientos se encuentran en dirección a este trabajo, como cuando afirma que "[...] las formas de jugar videojuegos no son formas específicas de asumir un juego o formato concreto, sino que las mismas categorías que se emplean para jugar son las que se aplican para procesar la vida cotidiana" (p. 4).

Peláez (2009) realiza una reflexión sobre las dinámicas de interacción digital, específicamente lo relacionado con los videojuegos y las interconexiones que se establecen al estar fusionadas con el futbol soccer. Uno de los argumentos centrales del texto radica en la idea de que los videojuegos son un arte expresivo que representa las visiones de los creadores, mostrándose como un producto cultural que va mutando y transformándose respecto a la misma cultura de donde se crean. El autor manifiesta para el 2009 el traslado que ha ocurrido de las experiencias lúdicas en los entornos físico-análogos hacia las formas de las expresiones electrónicas, que para ese entonces aún eran fenómenos no muy estudiados.

Anyó (2006) concibe a los videojuegos como una industria cultural y a su consumo como un elemento para analizar cómo se produce la construcción de la identidad, mientras que el consumidor es entendido como un individuo que no se encuentra aislado, sino que es miembro de un grupo social y cultural. Por otra parte, en el trabajo se trata el mercadeo(marketing) como un elemento importante para toda industria y en el caso de los videojuegos, como industria cultural, a través del marketing tratan de encajar su producción en los estilos de vida del público al que van dirigidos. Asimismo, el autor analiza cómo el consumo de tecnología no depende de los estratos socioeconómicos, mientras utiliza la teoría del consumo cultural para determinar cómo el consumo influye en la construcción de las identidades.

En ese sentido, aunque el consumo de videojuegos se ha relacionado actualmente con las familias que poseen los recursos para adquirir las consolas, el consumo de videojuegos nace en las salas de Arcades que eran frecuentadas en su mayoría por jóvenes de bajos y medios estratos. Así, muestran cómo ocurrió un desplazamiento de la juventud, de las calles a la habitación, pues en la actualidad los padres se sienten más seguros con que sus hijos jueguen videojuegos en la casa de amigos que en la calle. Se muestra entonces al videojuego como un instrumento usado por los padres para que sus hijos retornen al espacio doméstico. Sin embargo, según el autor esa retirada ocurre sólo en los estratos medio altos y altos, pues, aunque la llegada de las consolas caseras acabara en gran parte con los negocios de Arcades, en los sectores populares aún están vigentes estos espacios, pues ya no son Arcades las que funcionan sino en su lugar consolas caseras en los establecimientos públicos. 
Casas \& Perillán (2004) describen las categorías epistémicas presupuestas en la video-animación y en los videojuegos japoneses, haciendo énfasis en la estructuras narrativas de las mismas y evidenciando las diferencias entre las formas de narración occidentales y las japonesas, comparando de esa manera a los VJ japoneses y al animé frente al comic y a los VJ occidentales, evidenciando muchas diferencias referente a la manera de narración, la concepción del tiempo, la noción de sujeto etc., su apuesta teórica va en concordancia con esta investigación, pues el texto hace referencia a la complejidad con relación a las redes e interacciones, haciendo referencia, podría decirse que a la hipertextualidad en los $\mathrm{VJ}$, a la red de relaciones entre varios componentes cooperativos en el acto de compresión de los mismos, ya que son muchos elementos de diversas fuentes que manejan el mismo lenguaje para el mismo propósito, la construcción y comprensión de ese universo virtual en donde operan los VJ.

También se centra en las categorías empíricas interpretativas de los consumidores de videojuegos en varios niveles: género, estrato socioeconómico y edad, con el fin último de indagar en la construcción de identidad respecto a los videojuegos en Antofagasta y Temuco. De esa manera, los trabajos anteriormente citados, contribuyen a esta investigación teniendo en cuenta que las categorías usadas por los autores expresan el salto de los juegos a las nuevas tecnologías, mostrando de esa manera el estado multimedial de su funcionamiento y la condición de hipertextualidad, que, sumado a la singularidad de las narrativas, inciden en la identidad de los individuos y en última instancia en la construcción de las subjetividades.

\section{Conclusiones}

Al sumergirse constantemente en espacios virtuales que promocionan intenciones e incitan a la toma de decisiones en determinadas situaciones y desde diferentes roles, los jugadores poco a poco van asimilando toda una gama de mensajes que, a través de la realidad virtual y la interactividad, inciden en la construcción de sus subjetividades.

Ahora bien, al igual que ocurre con cualquier juego grupal, en los MMOG, (Videojuego multijugador masivo en línea, por las siglas en inglés de Massively multiplayer online). Aunque la historia también posee una intención, la construcción de estas subjetividades es influenciada más por los compañeros de juego que por cualquier otro elemento, pues hay un gran número de personas conectadas de manera simultánea, en donde la conformación de clanes y la influencia de unos frente a otros ocurre de manera masiva. En este cúmulo de relaciones no están ausentes las manifestaciones sobre posiciones políticas, opiniones religiosas, orientaciones ideológicas o lugares de origen. Dichas manifestaciones pueden ser objeto de juicio para catalogar negativa o positivamente a un jugador, ya que la orientación política o la nacionalidad determina en muchas circunstancias la aceptación o rechazo por parte de clanes o grupos influyentes. 


\section{CIENCIAS SOCIALES}

Un ejemplo de esto es la denigración que expone Loayza (2009) de los latinos en servidores angloparlantes norteamericanos, que ha llevado a la creación extraoficial de servidores exclusivamente hispanohablantes. Este tipo de situaciones inciden en las opiniones que los jugadores poseen de su contexto cultural; de ese modo, de acuerdo con Aragón (2001), no solo la subjetividad se reconstruyen con el constante consumo, sino también los elementos identitarios en constante pugna a través de las interrelaciones intersubjetivas e interculturales que se dan dentro de la dinámica del juego, lo que va integrando emociones y elementos semióticos al mismo proceso de construcción de la subjetividad e identidad de los jugadores, en esas mismas relaciones de poder.

\section{Agradecimiento}

Esta publicación obtuvo el financiamiento de: El Fondo de Asistencia Internacional de los Estudiantes y Académicos Noruegos (SAIH).

\section{Lista de referencias}

Acevedo Merlano, A. (2019). Age of Empires en el aula: un recurso para enseñar y aprender historia. Revista novedades educativas, 341, pp. 58-61.

Acevedo-Merlano, A. \& Chaux, J. (2018). Juego, luego existo: Reflexiones en torno a los videojuegos y las subjetividades. En Territorio, identidades, comunicación. Rionegro: Universidad católica de oriente.

Acevedo Merlano, A. \& Chaux, J. (2016). Aproximaciones a los videojuegos y su incidencia en las subjetividades de los jugadores latinoamericanos. Aposta. Revista de Ciencias Sociales, 69, pp. 140-157.

Anyó, L. (2006) ¿Quién consume videojuegos? Los estilos de vida en contextos urbanos y el consumo de videojuegos, en: XXI Congreso Internacional de Comunicación CICOM: Los jóvenes y el nuevo escenario de la comunicación, Pamplona, Universidad de Navarra.

Aragón, Y. (2011). Desarmando el poder antisocial de los videojuegos. Reifop, 14, 2, pp. 97-103.

Belli, S. y Amp; López, C. (2008). Breve historia de los videojuegos. Athenea Digital, 14, pp. 159-179.

Casas, R. \& Perillán, L. (2004). El rol del videojuego en el proceso de construcción de identidades: Antofagasta y Temuco, Chile. deSignis, pp. 177-187. 
Del Villar, R. (2011). Brecha digital, categorías perceptivas y cognitivas, el caso de los video- juegos. Comunicación Y Medios, 17, pp.1-11.

García-Carrizo, J. (2016). Piratería en la industria cultural de los videojuegos: análisis de los niveles, hábitos y motivaciones en los estudiantes de universidades públicas españolas. Documentación De Las Ciencias De La Información, 39, pp. 333-355

Loayza, J. (2009). Los videojuegos on-line en Latinoamérica: impacto en las redes sociales y de consumo. Revista icono, 15, pp. 59-74.

Mayra, F. (2008). An Introduction to Game Studies. London: Sage.

Muros, B., Aragón, Y., \& Bustos-Jiménez, A. (2013). La ocupación del tiempo libre de jóvenes en el uso de videojuegos y redes. Comunicar, 2o(40), pp. 31-39.

Peláez, B. (2009). Futbol y videojuegos: reinventando el juego. Razón y Palabra, 69, pp. 1-14.

Real Academia Española (2019). Diccionario de la lengua española (23.3 ed.) (21-02-2019).

Rodríguez, V. y Pestano, J. (2012). Los videojuegos en España: una industria cultural incipiente. Ámbitos. Revista Internacional de Comunicación, (21), pp. 361-379.

Torres-Parra, C. (2013). De la promesa digital a los videojuegos del oprimido. Claves sobre un uso de resistencia a través del consumo cultural. Palabra Clave, 16(3), pp. $760-786$. 